\title{
Four-year results of a prospective single-arm study on 200 semi-constrained total cervical disc prostheses: clinical and radiographic outcome
}

\author{
Hans-Jörg Meisel, MD, PhD, ${ }^{1}$ Lubomír Jurák, MD, ${ }^{2}$ Jussi Antinheimo, MD, ${ }^{3}$ Ricardo Arregui, MD, ${ }^{4}$ \\ Bernhard Bruchmann, MD, ${ }^{5}$ Mario Čabraja, MD, ${ }^{6}$ Fabrizio Caroli, MD, ${ }^{7}$ Stefan Kroppenstedt, MD, ${ }^{8}$ \\ Jan Kryl, MD, ${ }^{9}$ Juha Pohjola, MD, ${ }^{3}$ lan Shackleford, MD, ${ }^{10}$ Steffen Sola, MD, ${ }^{11}$ Peter Stosberg, MD, ${ }^{1}$ \\ Jan Stulik, MD, ${ }^{9}$ Christian Woiciechowsky, MD, ${ }^{12}$ and Petr Suchomel, MD²
}

\begin{abstract}
${ }^{1}$ Department of Neurosurgery, BG Clinic Bergmannstrost, Halle, Germany; ${ }^{2}$ Neurocentre, Regional Hospital Liberec, Czech Republic; ${ }^{3}$ Department of Neurosurgery, University of Helsinki, Finland; ${ }^{4}$ Neurosurgical Department, Hospital Maz, Zaragoza, Spain; ${ }^{5}$ Spinal Surgery, Katholisches Klinikum Koblenz, Germany; ${ }^{6}$ Zentrum für Wirbelsäulenchirurgie, Vivantes AugusteViktoria-Klinikum, Berlin, Germany; ${ }^{7}$ Neurosurgery, "Regina Elena" National Cancer Institute, Rome, Italy; ${ }^{8}$ Abteilung für Wirbelsäulenchirurgie, Sana Kliniken Sommerfeld, Kremmen, Germany; ${ }^{9}$ Center for Spine Surgery, Motol University Hospital, Prague, Czech Republic; ${ }^{10}$ Spinal Surgery, Warrington District General Hospital, Warrington, United Kingdom; and ${ }^{11}$ Department of Neurosurgery, University of Rostock, Germany; and ${ }^{12}$ Neurosurgery and Spine Surgery, Spine Center Berlin, Germany
\end{abstract}

OBJECTIVE Recent studies have described encouraging outcomes after cervical total disc replacement (cTDR), but there are also critical debates regarding the long-term effects of heterotopic ossification $(\mathrm{HO})$ and the prevalence of adjacent-level degeneration. The aim in this paper was to provide 4-year clinical and radiographic outcome results on the activ $\mathrm{C}$ disc prosthesis.

METHODS A total of 200 subjects underwent single-level activ C (Aesculap AG) implantation between C-3 and C-7 for the treatment of symptomatic degenerative disc disease. Clinical and radiographic assessments were performed preoperatively, intraoperatively, at discharge, and again at 6 weeks, 6 months, 1 year, 2 years, and 4 years. Radiographic evaluations were done by an independent core laboratory using a specific software for quantitative motion analysis.

RESULTS Neck Disability Index (NDI) and visual analog scale (VAS) score for neck and arm pain decreased significantly from baseline to the 4-year follow-up. The mean improvement for NDI was 20 , for VAS severity and frequency of neck pain 26.4 and 28, and for VAS severity and frequency of arm pain 30.7 and 35.1, respectively. The neurological situation improved for the majority of patients (86.4\%); $76.1 \%$ of cases were asymptomatic. Subsequent surgical interventions were reported in $7 \%$ of the cases, including device removals in $3 \%$. In $2.5 \%$ a subsidence greater than $3 \mathrm{~mm}$ was recorded; 1 of these cases also had a migration greater than $3 \mathrm{~mm}$. No device displacement, expulsion, disassembly, loose or fractured device, osteolysis, or facet joint degeneration at the index level was observed. Segmental lordotic alignment changed from $-2.4^{\circ}$ preoperatively to $-6.2^{\circ}$ at 4 years, and postoperative height was maintained during the follow-up. Advanced HO (Grade III and IV) was present in $27.1 \%$ of the cases; $82.4 \%$ showed segmental mobility. A progression of radiographic adjacent-segment degeneration occurred in $28.2 \%$, but only $4.5 \%$ required surgical treatment. CONCLUSIONS The activ $\mathrm{C}$ is a safe and effective device for cervical disc replacement confirming the encouraging results after cTDR.

Clinical trial registration no.: NCT02492724 (clinicaltrials.gov)

http://thejns.org/doi/abs/10.3171/2016.3.SPINE15810

KEY WORDS cervical spine; total disc replacement; degenerative disc disease; activ C; clinical outcome; long-term results; Neck Disability Index; visual analog scale; heterotopic ossification; range of motion; adjacent-segment degeneration

ABBREVIATIONS ACDF = anterior cervical discectomy and fusion; $A E=$ adverse event; $A P=$ anteroposterior; $A S D=$ adjacent-segment disease; $B M I=$ body mass index; $\mathrm{COI}=$ conflict of interest; $\mathrm{COR}=$ center of rotation; $\mathrm{cTDR}=$ cervical total disc replacement; FJD = facet joint degeneration; $\mathrm{HO}=$ heterotopic ossification; NDI = Neck Disability Index; RCT = randomized controlled trial; ROM = range of motion; VAS = visual analog scale.

SUBMITTED July 9, 2015. ACCEPTED March 3, 2016.

INCLUDE WHEN CITING Published online June 3, 2016; DOI: 10.3171/2016.3.SPINE15810. 
A NTERIOR cervical discectomy and fusion (ACDF) is a standard technique for the treatment of cervical degenerative disc disease that is unresponsive to conservative therapy. ${ }^{14,27,49}$ Despite its success, adjacent-segment overload has been reported by several authors, $, 3,8,23,24,26,30,32,37$ supported by in vitro demonstration of increased motion and/or intradiscal pressure at adjacent levels. ${ }^{18-20,44}$ cTDR was developed to preserve motion, to relieve the adjacent levels, and consequently to decrease the risk for adjacent-segment disease (ASD). ${ }^{19,46}$ Today, several devices for cTDR with different design concepts are on the market, some of them with clinical and radiographic mid- to long-term results. 1,11,13,17,22,41,47,52,57,59 Various randomized controlled trials have indicated equivalence or even superiority of cTDR in some clinical aspects compared with ACDF. $9,25,36,40,54$ However, there remains critical debate on cTDR mainly regarding indication,

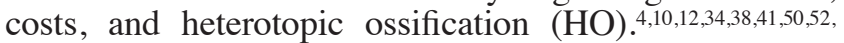
57,58 HO may not affect clinical outcome ${ }^{5,33,38,52,57}$ or be less relevant in the absence of clinical symptoms, ${ }^{6,28}$ but advanced HO potentially compromises segmental mobility with an unknown impact on sagittal profile, long-term clinical results, and ASD.

With this prospective, single-arm, multicenter study the clinical and radiographic 4-year results after cTDR are assessed.

\section{Methods}

Two hundred patients were enrolled by 11 study sites according to the criteria of Table 1 between January 2007 and December 2009. Subjects received single-level cTDR (activ C, Aesculap AG, Fig. 1) and underwent follow-up for 4 years. The study received a central and local ethics approval for each study center, and all subjects gave written consent prior to study enrollment (Clinical trial registration no.: NCT02492724 [clinicaltrials.gov]).

Clinical outcomes included improvement of Neck Disability Index (NDI) and visual analog scale (VAS) scores regarding the severity and frequency of neck and arm pain from baseline to 4-year follow-up, neurological examinations (manual muscle test, sensory and reflex assessments), the patient's view on the success of surgery, complications, and subsequent surgical interventions. The NDI was used according to the original publication by Vernon et al. ${ }^{55}$ The score obtained was multiplied by 2 to produce a percentage score.

All radiographic evaluations were performed by an independent core laboratory that analyzed digital anteroposterior (AP), lateral, and dynamic (flexion/extension) images. Measures were made using validated quantitative motion analysis software (QMA, Medical Metrics Inc.), ${ }^{21,45,48,53}$ and qualitative assessments were performed by an experienced radiologist. Radiographic parameters included segmental lordosis, C2-7 angle, average disc height at index level, radiolucency at the bone-implant interface, $\mathrm{HO}$ according to Mehren et al. ${ }^{38}$ conforming to McAfee et al., ${ }^{35}$ osteolysis, facet joint degeneration (FJD), device condition and placement, subsidence, migration, range of motion (ROM), translation, and center of rotation (COR) in the $\mathrm{x}$ and $\mathrm{y}$ axes at the index level. Furthermore,
TABLE 1. Inclusion and exclusion criteria

Inclusion Criteria

Symptomatic single-level cervical degenerative disc disease with neck \&/or arm pain \&/or neurological deficit, confirmed by MRI

Single-level surgery \& single-level implantation of prosthesis between C-3 \& C-7

Age between $18 \& 65 \mathrm{yrs}$ at the time of surgery

Preoperative disc space height of the segment to be operated on of at least $3 \mathrm{~mm}$

Unsuccessful adequate conservative treatment

Patient understands the conditions of the study \& is willing \& able to comply with the postoperative scheduled clinical \& radiographic evaluations \& the prescribed rehabilitation

Patient-signed informed consent

\section{Exclusion Criteria}

Major facet joint degeneration at the segment to be operated on

Severe spondylosis at the segment to be operated on (bridging osteophytes, absence of motion $\left[<2^{\circ}\right]$ )

Preoperative disc space height of the segment to be operated on of $<3 \mathrm{~mm}$

Major cervical segmental instability at the segment to be operated on (translation $\geq 3.5 \mathrm{~mm} \& / \mathrm{or} \geq 11^{\circ}$ of rotational difference to that of either adjacent level)

Previous trauma to the segment to be operated on resulting in compression or bursting

Previous spinal surgery, other than discectomy, at the cervical spine or any previous spinal surgery at the level to be replaced

Patient with any known active malignancy within the last 5 years

Active systemic or previous surgical site infection

Chronic steroid use

Patient who has a known sensitivity to the device material

Psychosocial disorders

Fever

Severe obesity $\left(\mathrm{BMI}>35 \mathrm{~kg} / \mathrm{m}^{2}\right)$

Bone growth stimulator use in cervical spine

Pharmaceutical or other drug abuse; alcoholism

Severe osteoporosis, osteopenia, or any metabolic bone disease

Patient who is suffering from rheumatological or other inflammatory joint disease

Patient with other concurrent physical or mental conditions which are likely to affect the outcome such as sickle cell anemia, systemic lupus erythematosus, or renal disease requiring dialysis

Female patient who is pregnant or plans to became pregnant during the course of the study

Patient who, as judged by the surgeon, is mentally incompetent or is unlikely to be compliant with the prescribed postoperative routine \& follow-up evaluation schedule

Patient who has not signed the informed consent

ASD above and below the index level was observed. ASD was identified if a subject's grading on disc degeneration and/or FJD (both Grade 0 to 4 according to Kellgren ${ }^{31}$ and Côté et al. ${ }^{16}$ ) was $\geq$ Grade 2 and minimum 1 grade higher than preoperatively, any new instability occurred $(\geq 3.5$ $\mathrm{mm}$ translation and/or $\geq 11^{\circ}$ rotational difference to neighboring segments), and/or any instrumentation was added. Magnification is corrected by a calibration ring. 


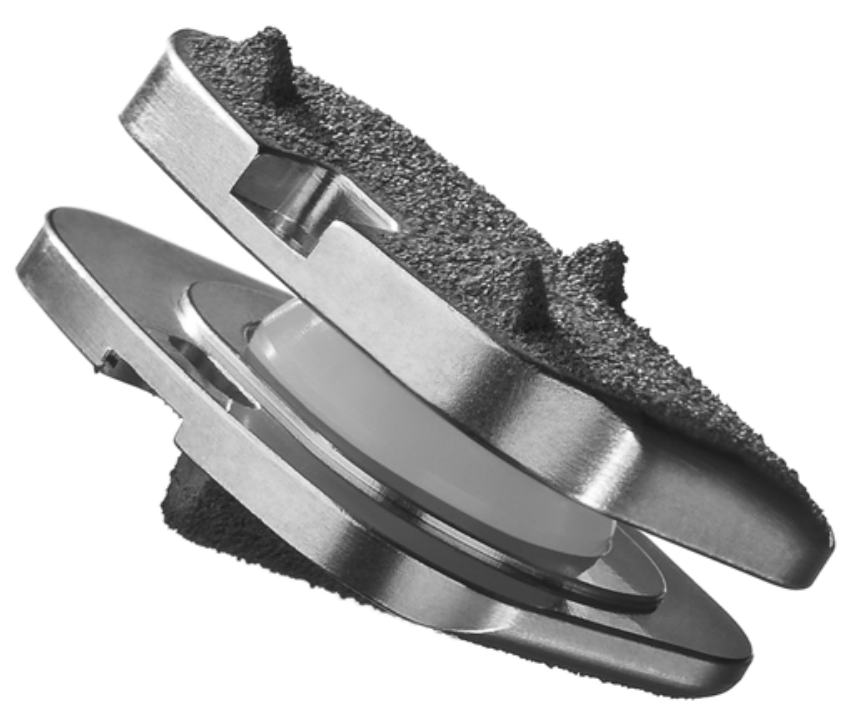

FIG. 1. The activ $C$ total disc replacement. Published with permission from Aesculap AG.

Due to the lack of a direct control group, we compared the study results with published control groups (cTDR and ACDF) with 4- to 6-year results. These studies included 4 randomized controlled trials (RCTs) ${ }^{15,26,46,53,56}$ comparing CTDR and ACDF plus 1 paper discussing 4-year cTDR results with special regard to $\mathrm{HO} .{ }^{28}$

\section{Implant and Surgery}

The activ $\mathrm{C}$ cervical disc prosthesis is a semiconstrained implant in a "ball and socket" design, with anatomically shaped prosthesis plates in 6 sizes and heights from 5 to $7 \mathrm{~mm}$, coated with osteointegrative plasma-sprayed pure titanium (Plasmapore, Aesculap AG). A combination of spikes and keel allows for primary stability. All implants incorporate a lordotic angle of $3^{\circ}$. Natural motion pattern is implemented through the inlay/prosthesis shape and its adaption to the facet joints. Standard and flat designs address light or moderate degeneration.
Surgery was performed by a total of 24 surgeons in 11 centers, with up to 4 surgeons in 1 center. For detailed information on case distribution by center and surgeon see Table 2. Following a standard right- or left-sided anterolateral approach and after total anterior discectomy and decompression the implant bed was prepared, and the implant size and height was tested by trial components. The preparation of an AP slot into the caudal vertebral body allows en bloc implantation, avoiding over-distraction. Postoperative care was handled according to the center's standard procedures. The physical initial and follow-up examinations were done by either the investigators or other surgeons at the hospital.

\section{Statistical Analysis}

Statistical analysis was performed using IBM SPSS Statistics (version 21). Comparisons for means (pre- vs postoperative results) used a nonparametric Wilcoxon signed-rank test; for independent groups a nonparametric Mann-Whitney U-test was used. Statistical significance is assumed at $\mathrm{p}<0.05$.

\section{Results}

\section{Patient Demographics}

One hundred twenty-eight of 200 patients (64\%) received a standard implant design and $72(36 \%)$ a flat implant design (for demographics see Table 3). No statistically significant differences were found between the groups regarding age, sex, body mass index (BMI), duration of symptoms, and level of surgery (unpaired t-test, chi-square test).

\section{Intraoperative Details and Discharge}

The mean operation time was $78 \pm 25$ minutes, and approaches were left-sided in $88.4 \%$ of patients and rightsided in $11.6 \%$. The independent reviewer reported "ideal lateral placement" for all implantations; no oblique implant position or axial rotation occurred. The appropriate implant size was chosen in $98.0 \%$ of cases (195/199), and

TABLE 2. Case distribution by center and surgeon

\begin{tabular}{clrrr}
\hline $\begin{array}{c}\text { Center } \\
\text { No. }\end{array}$ & \multicolumn{1}{c}{ Center } & $\begin{array}{c}\text { No. of } \\
\text { Cases }\end{array}$ & $\begin{array}{c}\text { No. of } \\
\text { Surgeons }\end{array}$ & $\begin{array}{c}\text { No. of Surgeries } \\
\text { per Surgeon }\end{array}$ \\
\hline 1 & Neurocentre, Regional Hospital Liberec, Czech Republic & 48 & 3 & $20 / 1 / 27$ \\
\hline 2 & Department of Neurosurgery, BG Clinic Bergmannstrost, Halle, Germany & 18 & 4 & $14 / 1 / 1 / 2$ \\
\hline 3 & Center for Spine Surgery, University Hospital Motol, Prague, Czech Republic & 20 & 2 & $19 / 1$ \\
\hline 4 & Neurosurgery, Instituti Fisioterapici Ospitalieri (IFO), Rome, Italy & 2 & 1 \\
\hline 5 & Spinal Surgery, Warrington District General Hospital, Warrington, United Kingdom & 13 & 2 \\
\hline 6 & Department of Neurosurgery, Charité University Hospital and School of Medicine, Berlin, Germany & 18 & 3 & $11 / 2$ \\
\hline 7 & Department of Neurosurgery, University of Helsinki, Finland & 21 & 2 & $16 / 1 / 1$ \\
\hline 8 & Neurosurgical Department, Hospital Maz, Zaragoza, Spain & 10 & 2 & 11 \\
\hline 9 & Neurosurgery and Spine Surgery, Spine Center Berlin, Germany & $3 / 15$ & 9 \\
\hline 10 & Department of Neurosurgery, University of Rostock, Germany & 30 & 3 \\
\hline 11 & Spinal Surgery, Katholisches Klinikum Koblenz, Germany & 9 & 1 \\
\hline Total & & 200 & 24 \\
\hline
\end{tabular}


TABLE 3. Patient demographics

\begin{tabular}{lc}
\hline \multicolumn{1}{c}{ Variable } & Value $^{*}$ \\
\hline Total & 200 \\
\hline Mean age in yrs & $43 \pm 7.8$ \\
\hline Sex & \\
$\quad$ Male & $118(41)$ \\
Female & $25.7 \pm 4.0$ \\
\hline Mean BMl in kg/m ${ }^{2}$ & $11.8 \pm 16.7$ \\
\hline Mean duration of symptoms prior to surgery in mos & \\
\hline Level of surgery & $3(1.5)$ \\
C3-4 & $13(6.5)$ \\
C4-5 & $108(54.0)$ \\
C5-6 & $76(38.0)$ \\
C6-7 &
\end{tabular}

* Values represent the number of patients (\%) unless specified otherwise. Mean values are reported as the mean \pm SD.

it was judged as too small (1/199) or too large (1/199) in $1.0 \%$ of cases. Additional procedures were performed in $87.4 \%$ of cases (174/199) as follows: $35.2 \%$ (70/199) partial posterior longitudinal ligament resection, $48.7 \%$ (97/199) total posterior longitudinal ligament resection, $18.6 \%$ (37/199) partial resection of uncovertebral process, $1.0 \%$ $(2 / 199)$ enlargement of the implant bed, and $0.5 \%(1 / 199)$ resection of ventrocaudal rim to erase the entrance of the median ventral spike. On average, patients spent $4 \pm 5.2$ days in the hospital postsurgery.

\section{Postoperative Outcome}

Four-year results are available for 168 of 193 patients (87\%) who were expected to have results at 4 years. Seven patients were not able to complete the study for the following reasons: one subject died 3 years postoperatively but this death was not related to the device or procedure, and 6 subjects underwent device removal or supplemental fixation at the index level prior to their 4-year examination (for more information on these 7 cases see Adverse Events and Secondary Surgical Interventions below).

\section{Clinical Outcome}

All patient self-administered outcome measures showed statistically significant $(\mathrm{p}<0.001$, Wilcoxon signed-rank test) and clinically important ${ }^{50,51}$ improvements from baseline to the 4-year follow-up (Fig. 2). Mean improvement $( \pm$ SD) for NDI was $20 \pm 21(n=156)$, for VAS severity of neck pain $26.4( \pm 33.9)(\mathrm{n}=158)$, for VAS frequency of neck pain $28 \pm 37.8(\mathrm{n}=158)$, for VAS severity of arm pain $30.7 \pm 34.8(\mathrm{n}=158)$, and for VAS frequency of arm pain $35.1 \pm 37.4(\mathrm{n}=158)($ Table 4$)$.

Preoperatively, 34\% (68/200) of all cases had a combined sensory and motor deficit, $11.5 \%$ (23/200), a motor deficit, and $35.5 \%(71 / 200)$ a sensory deficit. Four years postoperatively, the neurological situation has improved for the majority of patients $(86.4 \%)$ with $76.1 \%(118 / 155)$ asymptomatic cases. In $8.4 \%(13 / 154)$ the neurological deficit continued and in $5.2 \%(8 / 154)$ it deteriorated compared with the preoperative situation (motor deficit in
2, combined sensory and motor deficit in 6). In terms of patients' personal feelings on surgery success at 4 years, 133 of 157 patients $(84.7 \%)$ responded "excellent or good result," 19 of 157 (12.1\%) "fair result," and 5 of 157 (3.2\%) "poor result."

Clinical outcome results of control groups are summarized in Table 5.

\section{Adverse Events}

Surgery-related complications occurred in 2 cases (1\%: 1 excessive perioperative hemorrhage and 1 postoperative hematoma). For completeness of the picture, systemic complications were also recorded, occurring in 8 cases (carpal tunnel syndrome in 3 , and sulcus ulnaris syndrome, shoulder pain, multiple pain, stroke, and Parkinson disease in 1 case each), 26 postoperative complications occurred in 21 patients (10.5\%: persistent pain in 12, dysphagia in 1, neurological symptoms in 13 patients), and 12 adjacent-level-related complications in 9 cases $(4.5 \%$ : pain in 3, symptomatic adjacent-level degeneration in 8 , and neurological symptoms in 1 case). Six possibly devicerelated complications were seen in 5 patients $(2.5 \%, 5$ with subsidence $>3 \mathrm{~mm}$, including 1 with migration $>3 \mathrm{~mm}$ ).

\section{Secondary Surgical Interventions}

Fifteen secondary surgical interventions on the cervical spine were reported in 14 subjects (7\%): the investigational device was removed in 6 cases (3\%), 1 followed by a 2-level fusion due to ASD was performed in 1 case, and 9 additional instrumentations were performed in 8 cases, one of them at index level. Three cases with other surgeries occurred, but not in the cervical spine.

In 3 cases implant removal was due to persistent radiculopathy, which recovered in 1 case after cTDR reimplantation, but did not in 2 cases after secondary fusion surgery. One patient who complained of postoperative neck pain and dysphagia received a smaller activ $\mathrm{C}$ implant and recovered completely afterward. In 1 patient caudal subsidence and posterior migration of more than $3 \mathrm{~mm}$ was diagnosed at final follow-up. Although the patient was pain free without any neurological symptoms, the cTDR was removed as a precautionary measure 5 years after implantation and subsequently fused. Another cTDR was replaced by 2-level fusion. In this case the initial decision for a single-level treatment was wrong. The patient suffered from pain progression caused by ASD and recovered after fusion surgery. As mentioned above, ASD was also the reason for 9 additional instrumentations in 8 subjects. Two patients received a second cTDR, and 6 subjects had fusion in an adjacent segment. In one of these subjects the initial adjacent-segment fusion was followed by a bilevel fusion that included the index level.

A systematic review of adverse events (AEs) and secondary surgeries of control groups is summarized in Table 6.

\section{Radiological Results at the Index Level}

Four years postoperatively, independent radiographic measurements show a more lordotic alignment for segmental lordosis $\left(-6.2^{\circ}\right.$ vs $-2.4^{\circ}$ preoperatively) and C2 -7 angle $\left(-8.7^{\circ}\right.$ vs $-6.4^{\circ}$ preoperatively) $(\mathrm{p}<0.001$ and $\mathrm{p}<$ 

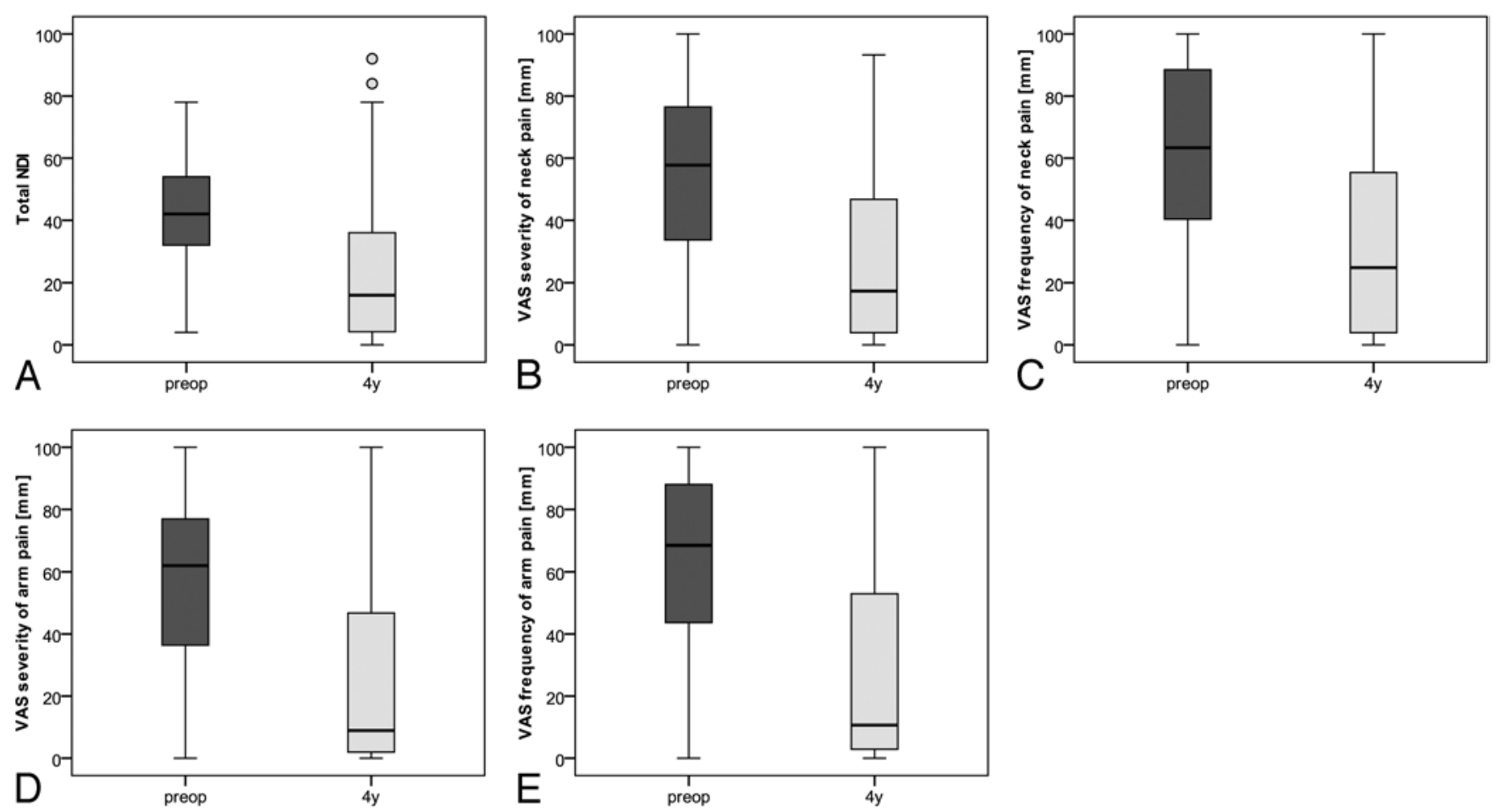

FIG. 2. Preoperative versus 4-year follow-up scores for a Neck Disability Index (A), severity of neck pain (B), frequency of neck pain (C), severity of arm pain (D), and frequency of arm pain (E). Horizontal lines denote the median; the boxes, the interquartile range; the whiskers, the entire range; and the dots, outliers.

0.05 , respectively, Wilcoxon signed-rank test). The average disc height at the index level changed from $3.7 \mathrm{~mm}$ preoperatively to $5.6 \mathrm{~mm}(\mathrm{p}<0.001$, Wilcoxon signedrank test). Loss of mean disc height during the postoperative follow-up was clinically irrelevant, with $0.2 \mathrm{~mm}$ between 6 weeks and 4 years. Seven radiolucencies along the implant-bone interface were detected; 3 of them were mild $(<25 \%), 4$ moderate $(25 \%-50 \%)$, and none resulted in implant loosening. Four years after surgery, Grade $0-$ II HO was recorded in 110 of 151 (72.8\%), Grade III in 21 of 151 (13.9\%), and Grade IV in 20 of 151 (13.2\%) cases. No statistically significant differences were found between cases with Grade 0-II HO and Grade III-IV HO regarding NDI and VAS neck and arm pain (Mann-Whitney Utest, $p>0.05)$. The independent reviewer identified no lat- eral device displacement, disassembled, loose or fractured device, device expulsion, osteolysis, or FJD at the index level. Figure 3 shows the radiological progression of $\mathrm{HO}$ in 1 patient with a final Grade IV after 4 years.

Segmental ROM changed from $9.3^{\circ}$ preoperatively to $6.5^{\circ}$ at 4 years $(\mathrm{p}<0.001$, Wilcoxon signed-rank test). Motion of at least $2^{\circ}$ was seen in $82.4 \%$ of subjects. Translation was $0.9 \mathrm{~mm}$ prior to surgery and $0.6 \mathrm{~mm}$ after 4 years $(p<0.001$, Wilcoxon signed-rank test). The COR in the AP direction (CORx) changed from $-0.8 \mathrm{~mm}$ preoperatively to $0.1 \mathrm{~mm} 4$ years postoperatively $(\mathrm{p}<0.001$, Wilcoxon signed-rank test). CORx moved from a position posterior to the midpoint of the inferior vertebra to a position slightly anterior to it. In the cranial-caudal direction, the COR (CORy) changed from $2.3 \mathrm{~mm}$ preoperatively to

TABLE 4. Clinical results during the course of the study

\begin{tabular}{|c|c|c|c|c|c|c|c|}
\hline \multirow[b]{2}{*}{ Variable } & \multicolumn{6}{|c|}{ Mean \pm SD (no. of patients) } & \multirow{2}{*}{$\begin{array}{c}\text { p Value (4 yrs } \\
\text { vs preop) }\end{array}$} \\
\hline & Preop & $6 \mathrm{Wks}$ & 6 Mos & $1 \mathrm{Yr}$ & 2 Yrs & 4 Yrs & \\
\hline NDI & $43 \pm 16.7(194)$ & $24.8 \pm 17.2(186)$ & $22.3 \pm 18.9(174)$ & $20.9 \pm 18.6(171)$ & $21.9 \pm 19.7(159)$ & $22.1 \pm 20.6(158)$ & $<0.001$ \\
\hline \multicolumn{8}{|l|}{ VAS neck pain } \\
\hline Severity & $55.6 \pm 27.1(193)$ & $25.8 \pm 23.8(185)$ & $24.1 \pm 25.8(174)$ & $25.4 \pm 25.4(172)$ & $26.8 \pm 25.8(160)$ & $27.7 \pm 27.6(158)$ & $<0.001$ \\
\hline Frequency & $63.4 \pm 30.5(193)$ & $28.9 \pm 27.1(185)$ & $27.2 \pm 28.7(174)$ & $28.1 \pm 27.3(172)$ & $30.1 \pm 28.4(160)$ & $32.5 \pm 29.7(158)$ & $<0.001$ \\
\hline \multicolumn{8}{|l|}{ VAS arm pain } \\
\hline Severity & $56.4 \pm 27.6(193)$ & $20.8 \pm 24.8(185)$ & $20.6 \pm 26.5(174)$ & $22.6 \pm 26.5(172)$ & $23.9 \pm 27.2(160)$ & $24.9 \pm 29.5(158)$ & $<0.001$ \\
\hline Frequency & $64.1 \pm 29.8(193)$ & $24.8 \pm 30.1(185)$ & $23.5 \pm 29.9(174)$ & $26.7 \pm 31.1(172)$ & $26 \pm 29.1(160)$ & $27 \pm 31(158)$ & $<0.001$ \\
\hline
\end{tabular}


TABLE 5. Comparison of clinical outcome*

\begin{tabular}{|c|c|c|c|c|c|c|}
\hline \multirow[b]{2}{*}{ Authors \& Year } & \multirow[b]{2}{*}{ FU (yrs) } & \multirow[b]{2}{*}{ No. of Patients } & \multirow[b]{2}{*}{ Mean NDI } & \multicolumn{2}{|c|}{ Mean VAS Score } & \multirow{2}{*}{$\begin{array}{l}\text { Neurological } \\
\text { Success }\end{array}$} \\
\hline & & & & Neck Pain & Arm Pain & \\
\hline \multicolumn{7}{|l|}{ cTDR } \\
\hline Burkus et al., 2010 & 5 & 144 & 17.3 & 12.2 & 6.6 & $95.0 \%$ \\
\hline Coric et al., 2013 & 6 & 41 & 20.5 & 10 & NR & NR \\
\hline Sasso et al., 2011 & 4 & 181 & $13.2 \pm 16.1$ & $20.7 \pm 25.3$ & $16.6 \pm 24.4$ & $92.8 \%$ \\
\hline Suchomel et al., 2010 & 4 & 50 & $30.4 \pm 20.3$ & $29 \pm 24$ & $23 \pm 28$ & NR \\
\hline Zigler et al., 2013 & 5 & 72 & $\sim 20$ & $\sim 21$ & $\sim 19$ & $90.3 \%$ \\
\hline Summary of control groups & $4-6$ & $50-181$ & $13.2-30.4$ & $10-29$ & $6.6-23$ & $90.3-95.0 \%$ \\
\hline Current study & 4 & 158 & $22.1 \pm 20.6$ & $27.7 \pm 27.6$ & $24.9 \pm 29.5$ & $94.4 \%$ \\
\hline \multicolumn{7}{|l|}{ ACDF } \\
\hline Burkus et al., 2010 & 5 & 127 & 22.3 & 16.9 & 14.7 & $88.9 \%$ \\
\hline Coric et al., 2013 & 6 & 41 & 21.75 & 10 & NR & NR \\
\hline Sasso et al., 2011 & 4 & 138 & $19.8 \pm 20.0$ & $30.6 \pm 30.8$ & $22.4 \pm 28.2$ & $89.9 \%$ \\
\hline Zigler et al., 2013 & 5 & 61 & $\sim 20$ & $\sim 31$ & $\sim 19$ & $91.7 \%$ \\
\hline Summary of control groups & $4-6$ & $41-138$ & $19.8-22.3$ & $10-31$ & $14.7-22.4$ & $88.9-91.7 \%$ \\
\hline
\end{tabular}

FU = Follow-up; NR = not reported.

* Mean values are reported as the mean \pm SD.

$1.0 \mathrm{~mm}$ at 4 years $(\mathrm{p}<0.001$, Wilcoxon signed-rank test), which corresponds to a cranial shift. For more detailed information on radiographic results, see Table 7.

\section{ASD}

Four years postoperatively, $15.3 \%$ of cases $(23 / 150)$ showed radiographic progression of ASD above and $15.4 \%$ (23/149) below the index level. Four subjects showed degeneration above and below; thus, radiographic progression of ASD was $28.2 \%$ (42/149). This includes symptomatic and asymptomatic cases. Most cases $(73.9 \% ; 17 / 23)$ with ASD above the index level showed a new radiographic disc degeneration compared with the preoperative situation; no patient showed a radiographic progression of FJD. In 1 case $(4.3 \%)$ a progressive instability caused ASD, and 5 patients $(21.7 \%)$ underwent adjacent-segment surgery. Similarly, below the index level most cases $(82.6 \% ; 19 / 23)$ showed a radiographic progression of disc degeneration, none had a radiographic progression of FJD or instability, and $4(17.4 \%)$ underwent adjacent-segment surgery. Principally, the decision for reoperation as a result of ASD was done individually if radicular pain and/or neurological deficits occurred in combination with corresponding radiographically confirmed ASD. The rate of surgery due to ASD for the entire study population was $4.5 \%$ (9/200); no distant segment surgery was performed.

ASD and $\mathrm{HO}$ results of control groups are summarized in Table 6.

\section{Discussion}

Although ACDF has been considered the gold-standard surgery for the treatment of cervical disc degeneration for the last few decades, several RCTs have reported equivalent or superior clinical outcomes of cTDR compared with ACDF. ${ }^{25,36,40,54}$ A recent Cochrane Review came to a similar conclusion, ${ }^{9}$ but it claims that mid- and long-term follow-up periods are needed to assess the clinical benefit of cTDR.

In this study NDI as well as VAS results on neck and arm pain improved significantly after 4 years. ${ }^{29,43}$ As shown in Table 5, clinical results are within the range of the cTDR and ACDF control groups, with the exception of VAS arm pain, which is slightly higher in our patients. Also, neurological success is comparable to the cTDR control groups, but slightly better than in ACDF. The range of surgery-related AEs differs, with $2.4 \%-11.7 \%$ for cTDR and $0.0 \%-20.8 \%$ for ACDF, which is probably due to inhomogeneous definitions used. However, our study results are within the range of both groups. The same applies to device failure and secondary surgeries at the index level. $1,11,13,17,22,47,52,59$

Cervical and segmental lordosis improved versus the preoperative situation, ROM decreased from $9.3^{\circ}$ to $6.5^{\circ}$ at 4-year-follow-up, and in $82.4 \%$ of patients a segmental motion of at least $2^{\circ}$ was maintained. A similar tendency was reported by Goffin et al..$^{22}$ on the Bryan disc with an ROM reduction from $9.3^{\circ}$ preoperatively to $7.3^{\circ} 4$ years postoperatively and a motion $\geq 2^{\circ}$ in $83.1 \%$ of single-level procedures, whereas Sasso et al. ${ }^{47}$ did not report a rate of motion maintenance in their extended investigational device exemption trial on the Bryan disc, but observed an improvement of ROM from $6.5^{\circ}$ preoperatively to $8.5^{\circ} 4$ years postoperatively. Five-year results in the SWISSspine registry ${ }^{1}$ showed mobile segments $\left(>2^{\circ}\right)$ in $88.2 \%$ (332 patients) with an average ROM in these mobile segments of $10.2^{\circ}$.

$\mathrm{HO}$ after cTDR is a matter of debate, as it counteracts motion preservation. Our study results show advanced Grade III HO in $13.9 \%$ of cases and Grade IV HO in $13.2 \%$ of cases 4 years after cTDR. Using the same classification system as was used for this study, Suchomel et 
TABLE 6. Comparison of selected AEs and secondary surgeries

\begin{tabular}{|c|c|c|c|c|c|c|c|c|c|}
\hline Authors \& Year & $\begin{array}{l}\text { FU } \\
\text { (yrs) }\end{array}$ & $\begin{array}{c}\text { Surgery- } \\
\text { Related AEs }\end{array}$ & $\begin{array}{l}\text { Bridging Bone, } \\
\text { HO Grade IV }\end{array}$ & $\begin{array}{c}\text { Device } \\
\text { Failure } \\
\text { (subsidence, } \\
\text { loosening) }\end{array}$ & $\begin{array}{c}\text { Adjacent- } \\
\text { Level Surgery }\end{array}$ & $\begin{array}{l}\text { Implant } \\
\text { Removal }\end{array}$ & $\begin{array}{c}\text { Supplemental } \\
\text { Fixation at } \\
\text { Index Level }\end{array}$ & $\begin{array}{l}\text { Revision } \\
\text { Surgery }\end{array}$ & Reoperation \\
\hline \multicolumn{10}{|l|}{ cTDR } \\
\hline $\begin{array}{c}\text { Burkus et al., } \\
2010\end{array}$ & 5 & $8.7 \%$ & $3 / 94(3.2 \%)$ & $2 / 71(2.8 \%)$ & $8 / 276(2.9 \%)$ & $7 / 276(2.5 \%)$ & & $0 / 276(0.0 \%)$ & $4 / 276(1.4 \%)$ \\
\hline $\begin{array}{l}\text { Coric et al., } \\
2013\end{array}$ & 6 & $1 / 41(2.4 \%)$ & $7 / 41(17.0 \%)$ & $0 / 41(0.0 \%)$ & $2 / 41(4.9 \%)$ & $0 / 41(0.0 \%)$ & $0 / 41(0.0 \%)$ & $0 / 41(0.0 \%)$ & $1 / 41(2.4 \%)$ \\
\hline $\begin{array}{l}\text { Delamarter } \\
\quad \& \text { Zigler, } \\
2013\end{array}$ & 5 & NR & NR & NR & $2 / 103(1.9 \%)$ & $2 / 103(1.9 \%)$ & $1 / 103(1.0 \%)$ & $0 / 103(0.0 \%)$ & $0 / 103(0.0 \%)$ \\
\hline $\begin{array}{l}\text { Sasso et al., } \\
2011\end{array}$ & 4 & NR & NR & NR & $10 / 242(4.1 \%)$ & $4 / 242(1.7 \%)$ & $0 / 242(0.0 \%)$ & $1 / 242(0.4 \%)$ & $4 / 242(1.7 \%)$ \\
\hline $\begin{array}{l}\text { Suchomel et } \\
\text { al., } 2010\end{array}$ & 4 & $2 / 50(4.0 \%)$ & $11 / 60(18.0 \%)$ & $0 / 50(0.0 \%)$ & $0 / 50(0.0 \%)$ & $0 / 50(0.0 \%)$ & $0 / 50(0.0 \%)$ & $0 / 50(0.0 \%)$ & $0 / 50(0.0 \%)$ \\
\hline $\begin{array}{l}\text { Zigler et al., } \\
2013\end{array}$ & 5 & $11.7 \%$ & $6 / 72(8.3 \%)$ & $1 / 72(1.4 \%)$ & $\begin{array}{l}\text { see Delamar- } \\
\text { ter \& Zigler, } \\
2013\end{array}$ & $\begin{array}{l}\text { see Delamar- } \\
\text { ter \& Zigler, } \\
2013\end{array}$ & $\begin{array}{l}\text { see Delamar- } \\
\text { ter \& Zigler, } \\
2013\end{array}$ & $\begin{array}{l}\text { see Delamar- } \\
\text { ter \& Zigler, } \\
2013\end{array}$ & $\begin{array}{l}\text { see Delamar- } \\
\quad \text { ter \& Zigler, } \\
2013\end{array}$ \\
\hline $\begin{array}{l}\text { Summary } \\
\text { of control } \\
\text { groups }\end{array}$ & $4-6$ & $2.4-11.7 \%$ & $3.2-18.0 \%$ & $0.0-2.8 \%$ & $0.0-4.9 \%$ & $0.0-2.5 \%$ & $0.0-1.0 \%$ & $0.0-0.4 \%$ & $0.0-2.4 \%$ \\
\hline Current study & 4 & $2 / 200(1.0 \%)$ & $20 / 151(13.2 \%)$ & $5 / 200(2.5 \%)$ & $9 / 200(4.5 \%)$ & $6 / 200(3.0 \%)$ & $1 / 200(0.5 \%)$ & $0 / 200(0.0 \%)$ & $0 / 200(0.0 \%)$ \\
\hline \multicolumn{10}{|l|}{ ACDF } \\
\hline $\begin{array}{l}\text { Burkus et al., } \\
2010\end{array}$ & 5 & $8.3 \%$ & & $1 / 71(1.4 \%)$ & $13 / 265(4.9 \%)$ & $13 / 265(4.9 \%)$ & $5 / 265(1.9 \%)$ & $5 / 265(1.9 \%)$ & $2 / 265(0.8 \%)$ \\
\hline $\begin{array}{l}\text { Coric et al., } \\
2013\end{array}$ & 6 & $0 / 41(0.0 \%)$ & & $1 / 33(3.0 \%)$ & $1 / 33(3.0 \%)$ & $0 / 33(0.0 \%)$ & $0 / 33(0.0 \%)$ & $0 / 33(0.0 \%)$ & $0 / 33(0.0 \%)$ \\
\hline $\begin{array}{l}\text { Delamarter } \\
\quad \text { \& Zigler, } \\
2013\end{array}$ & 5 & NR & & NR & $5 / 106(4.7 \%)$ & $6 / 106(5.7 \%)$ & $3 / 106(2.3 \%)$ & $2 / 106(0.9 \%)$ & $1 / 106(0.9 \%)$ \\
\hline $\begin{array}{l}\text { Sasso et al., } \\
2011\end{array}$ & 4 & NR & & NR & $9 / 212(4.1 \%)$ & $4 / 212(1.8 \%)$ & $5 / 221(2.3 \%)$ & $0 / 221(0.0 \%)$ & $1 / 221(0.5 \%)$ \\
\hline $\begin{array}{l}\text { Zigler et al., } \\
2013\end{array}$ & 5 & $20.8 \%$ & & $0 / 106(0.0 \%)$ & $\begin{array}{l}\text { see Delamar- } \\
\text { ter \& Zigler, } \\
2013\end{array}$ & $\begin{array}{l}\text { see Delamar- } \\
\text { ter \& Zigler, } \\
2013\end{array}$ & $\begin{array}{l}\text { see Delamar- } \\
\quad \text { ter \& Zigler, } \\
2013\end{array}$ & $\begin{array}{l}\text { see Delamar- } \\
\quad \text { ter \& Zigler, } \\
2013\end{array}$ & $\begin{array}{l}\text { see Delamar- } \\
\text { ter \& Zigler, } \\
2013\end{array}$ \\
\hline $\begin{array}{l}\text { Summary } \\
\text { of control } \\
\text { groups }\end{array}$ & $4-6$ & $0.0-20.8 \%$ & & $0.0-3.0 \%$ & $3.0-4.9 \%$ & $0.0-5.7 \%$ & $0.0-2.3 \%$ & $0.0-1.9 \%$ & $0.0-0.9 \%$ \\
\hline
\end{tabular}

* There was a total of $23 \mathrm{AEs}(11.5 \%)$. This includes postoperative AEs.

al. ${ }^{52}$ observed $45 \%$ of cases with HO Grade III and $18 \%$ with Grade IV at 4 years. Table 6 shows that 2 cTDR control groups had lower rates for bridging bone or Grade IV HO $(3.2 \%$ and $8.3 \%)$, but the other 2 studies reported even higher rates (17.0\% and $18.0 \%)$.

Further literature also shows wide ranges of $\mathrm{HO}$ Grade IV (fusion) rates, between less than $1 \%$ after 1 year and $2.9 \%$ to $18.5 \%$ after 2 years, up to $60 \%$ after 5 years. ${ }^{7,28,39,40,42,50} \mathrm{Chen}$ et al. ${ }^{12}$ report a pooled prevalence of $\mathrm{HO}$ of $44.6 \%$ (17.8 to $72.3 \%$ ) and of advanced $\mathrm{HO}$ (Grade III and IV) of $11.1 \%$ (4.2 to $23.1 \%$ ) after 1 year and of $58.2 \%$ (28.8\% to $78.5 \%$ ) and $16.7 \%$ (8.5 to $32.3 \%$ ) 2 years after cTDR, respectively. Current publications tend to report higher incidences of $\mathrm{HO}$ with $17.8 \% \mathrm{HO} 1$ year after implantation of the Bryan disc (including 6.7\% Grade III or IV), ${ }^{34} 7.9 \%$ Grade IV 2 years after Mobi-C implantation, ${ }^{5}$ or an overall $\mathrm{HO}$ occurrence of $94.1 \% .{ }^{41} \mathrm{Yi}$ et al. ${ }^{57}$ observed an overall $\mathrm{HO}$ rate for 3 different cTDRs of $40.6 \%$ and Brenke et al..$^{10}$ found $\mathrm{HO}$ (Grade III and IV) in $17.4 \%$ after 18 months using fluoroscopy and even higher incidences using CT-based analysis. The SWISSspine registry ${ }^{1}$ showed $13.9 \%$ of cases with Grade III and $0.9 \%$ with Grade IV HO. Alvin et al. ${ }^{2}$ concluded from a literature review that studies with a conflict of interest (COI) reported lower $\mathrm{HO}$ rates after cTDR compared with those without a COI.

The mechanism of $\mathrm{HO}$ development in the cervical spine is not yet clear, but possible causes seem to be 

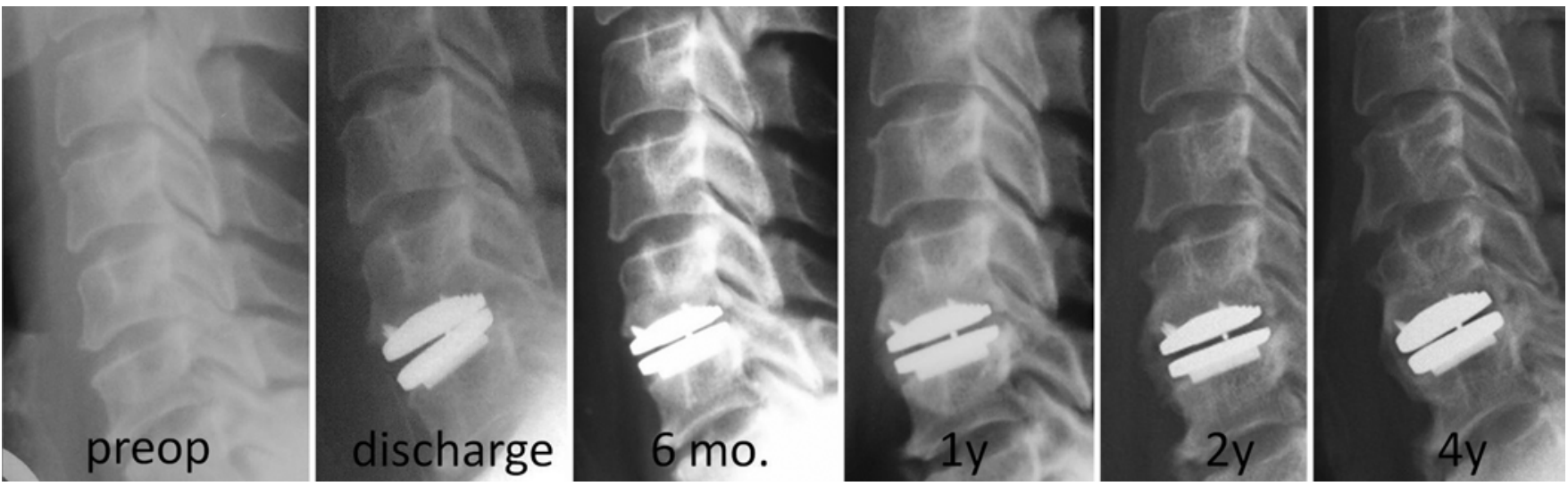

FIG. 3. Radiological follow-up of a patient with Grade IV HO.

manifold, including preoperative degenerative processes, surgical technique, implant design, ${ }^{51,57}$ limited motion, ${ }^{33}$ or genetic factors, ${ }^{25}$ and have already been discussed in an earlier publication. ${ }^{51}$ The clinical relevance of $\mathrm{HO}$ is controversial, indicating that $\mathrm{HO}$ does not affect clinical improvement ${ }^{5,33,38,51,52,57}$ and is less relevant in the absence of clinical symptoms, ${ }^{6,28}$ while challenging the principle of motion preservation. On the other hand, most studies show that in the majority of patients segmental mobility was sustained 4 to 6 years after cTDR.

cTDR is expected to reduce the risk of ASD. Yang et al. ${ }^{56}$ investigated the literature on ASD 4 to 6 years after cTDR in RCTs and found lower rates of degeneration and surgery in cTDR $(8.8 \%$ and $3.2 \%$, respectively) versus $\mathrm{ACDF}$ (13\% and $4.8 \%$, respectively), but the differences were not statistically significant. Alvin et al. ${ }^{2}$ confirmed this for studies with a COI, but not for those without. SWISSspine ${ }^{1}$ showed that $11.1 \%$ of patients had signs of ASD progression after 5 years, but the definition remained unclear; missing answers were counted as "no ASD." Beaurain et al. ${ }^{5}$ reported $9.1 \%$ of cases with radiological ASD 2 years postoperatively, and Goffin et al. ${ }^{22}$ identified 4 patients (4.1\%) with procedures involving other cervical levels 4 to 6 years after cTDR. Because standardized techniques and definitions for ASD are lack- ing, it is difficult to make comparisons with other studies. Secondary procedure at adjacent levels, therefore, is a clearer end point.

As shown in Table 6 adjacent-level surgery after 4 to 6 years occurred within a range of $0.0 \%$ to $4.9 \%$ in the cTDR control groups and between $3.0 \%$ to $4.9 \%$ in the ACDF groups, which indicates that our study is within $4.5 \%$ of the expectations.

The results of this prospective multicenter study verify that activ $\mathrm{C}$ is a safe and effective device for cervical disc replacement. The literature confirms convincing results of cTDR, suggesting equivalence or superiority in some aspects when compared with ACDF. To learn more about the long-term impact of $\mathrm{HO}$ and potential benefits regarding adjacent segments, longer-term studies are mandatory to confirm cTDR.

\section{Conclusions}

The activ $\mathrm{C}$ is a safe and effective device for cervical disc replacement, confirming the encouraging results after cTDR.

\section{Acknowledgments}

We thank Mrs. Nele Borm, frictionless GmbH, Kiel, Germany,

TABLE 7. Quantitative radiographic results during the course of the study

\begin{tabular}{|c|c|c|c|c|c|c|}
\hline \multirow[b]{2}{*}{ Variable } & \multicolumn{6}{|c|}{ Mean \pm SD (no. of patients) } \\
\hline & Preop & $6 \mathrm{Wks}$ & 6 Mos & $1 \mathrm{Yr}$ & 2 Yrs & 4 Yrs \\
\hline Segmental lordosis $\left({ }^{\circ}\right)^{*}$ & $-2.4 \pm 4.2(182)$ & $-6.3 \pm 4.9(187)$ & $-5.9 \pm 4.5(172)$ & $-5.9 \pm 4.3(159)$ & $-6.0 \pm 4.6(159)$ & $-6.2 \pm 4.8(148)$ \\
\hline $\mathrm{C} 2-7$ angle $\left({ }^{\circ}\right)^{*}$ & $-6.4 \pm 11.6(175)$ & $-9.7 \pm 10.5(179)$ & $-8.8 \pm 10.8(164)$ & $-9.5 \pm 10.6(153)$ & $-8.2 \pm 9.9(152)$ & $-8.7 \pm 11.2(140)$ \\
\hline Disc height (mm) & $3.7 \pm 0.7(182)$ & $5.8 \pm 0.8(187)$ & $5.7 \pm 0.8(172)$ & $5.7 \pm 0.9(159)$ & $5.6 \pm 0.9(159)$ & $5.6 \pm 0.9(148)$ \\
\hline $\operatorname{ROM}\left({ }^{\circ}\right)$ & $9.3 \pm 5.3(176)$ & $8.4 \pm 4.0(180)$ & $8.5 \pm 4.3(175)$ & & $6.9 \pm 4.9(151)$ & $6.5 \pm 4.7(142)$ \\
\hline Translation (mm) & $0.9 \pm 0.7(176)$ & $0.9 \pm 0.5(180)$ & $0.9 \pm 0.5(175)$ & & $0.7 \pm 0.6(151)$ & $0.6 \pm 0.6(142)$ \\
\hline CORx (mm)† & $-0.8 \pm 1.0(160)$ & $0.0 \pm 0.9(168)$ & $0.0 \pm 0.8(159)$ & & $0.2 \pm 0.9(116)$ & $0.1 \pm 0.9(100)$ \\
\hline CORy (mm) & $2.3 \pm 2.2(160)$ & $1.1 \pm 1.5(168)$ & $0.8 \pm 1.4(159)$ & & $1.2 \pm 1.4(116)$ & $1.0 \pm 1.2(100)$ \\
\hline
\end{tabular}

$\mathrm{CORx}=\mathrm{COR}$ in the anteroposterior direction; CORy $=\mathrm{COR}$ in the craniocaudal direction.

* Negative values indicate a lordotic alignment.

$\dagger$ Negative values indicate a COR position posterior to the midpoint of the endplate. 
for her contributions to this study, especially in monitoring data collection, performing statistical analyses, supervising the conduct of the study, and writing the final draft of the article.

\section{References}

1. Aghayev E, Bärlocher C, Sgier F, Hasdemir M, Steinsiepe KF, Wernli F, et al: Five-year results of cervical disc prostheses in the SWISSspine registry. Eur Spine J 22:1723-1730, 2013

2. Alvin MD, Abbott EE, Lubelski D, Kuhns B, Nowacki AS, Steinmetz MP, et al: Cervical arthroplasty: a critical review of the literature. Spine J 14:2231-2245, 2014

3. Baba H, Furusawa N, Imura S, Kawahara N, Tsuchiya H, Tomita K: Late radiographic findings after anterior cervical fusion for spondylotic myeloradiculopathy. Spine (Phila Pa 1976) 18:2167-2173, 1993

4. Bartels RH, Donk R, Verbeek AL: No justification for cervical disk prostheses in clinical practice: a meta-analysis of randomized controlled trials. Neurosurgery 66:1153-1160, 2010

5. Beaurain J, Bernard P, Dufour T, Fuentes JM, Hovorka I, Huppert J, et al: Intermediate clinical and radiological results of cervical TDR (Mobi-C) with up to 2 years of follow-up. Eur Spine J 18:841-850, 2009

6. Bertagnoli R: Heterotopic ossification at the index level after ProDisc-C surgery: what is the clinical relevance? Spine J 8 (5 Suppl):123S, 2008 (Abstract)

7. Bertagnoli R, Duggal N, Pickett GE, Wigfield CC, Gill SS, Karg A, et al: Cervical total disc replacement, part two: clinical results. Orthop Clin North Am 36:355-362, 2005

8. Bohlman HH, Emery SE, Goodfellow DB, Jones PK: Robinson anterior cervical discectomy and arthrodesis for cervical radiculopathy. Long-term follow-up of one hundred and twenty-two patients. J Bone Joint Surg Am 75:1298-1307, 1993

9. Boselie TF, Willems PC, van Mameren H, de Bie RA, Benzel EC, van Santbrink H: Arthroplasty versus fusion in singlelevel cervical degenerative disc disease: a Cochrane review. Spine (Phila Pa 1976) 38:E1096-E1107, 2013

10. Brenke C, Scharf J, Schmieder K, Barth M: High prevalence of heterotopic ossification after cervical disc arthroplasty: outcome and intraoperative findings following explantation of 22 cervical disc prostheses. J Neurosurg Spine 17:141146,2012

11. Burkus JK, Haid RW, Traynelis VC, Mummaneni PV: Longterm clinical and radiographic outcomes of cervical disc replacement with the Prestige disc: results from a prospective randomized controlled clinical trial. J Neurosurg Spine 13:308-318, 2010

12. Chen J, Wang X, Bai W, Shen X, Yuan W: Prevalence of heterotopic ossification after cervical total disc arthroplasty: a meta-analysis. Eur Spine J 21:674-680, 2012

13. Cheng L, Nie L, Li M, Huo Y, Pan X: Superiority of the Bryan ${ }^{\circledR}$ disc prosthesis for cervical myelopathy: a randomized study with 3-year followup. Clin Orthop Relat Res 469:3408-3414, 2011

14. Cloward RB: The treatment of ruptured lumbar intervertebral disc by vertebral body fusion. III. Method of use of banked bone. Ann Surg 136:987-992, 1952

15. Coric D, Kim PK, Clemente JD, Boltes MO, Nussbaum M, James S: Prospective randomized study of cervical arthroplasty and anterior cervical discectomy and fusion with long-term follow-up: results in 74 patients from a single site. J Neurosurg Spine 18:36-42, 2013

16. Côté P, Cassidy JD, Yong-Hing K, Sibley J, Loewy J: Apophysial joint degeneration, disc degeneration, and sagittal curve of the cervical spine. Can they be measured reliably on radiographs? Spine (Phila Pa 1976) 22:859-864, 1997
17. Delamarter RB, Zigler J: Five-year reoperation rates, cervical total disc replacement versus fusion, results of a prospective randomized clinical trial. Spine (Phila Pa 1976) 38:711-717, 2013

18. DiAngelo DJ, Roberston JT, Metcalf NH, McVay BJ, Davis RC: Biomechanical testing of an artificial cervical joint and an anterior cervical plate. J Spinal Disord Tech 16:314-323, 2003

19. Dmitriev AE, Cunningham BW, Hu N, Sell G, Vigna F, McAfee PC: Adjacent level intradiscal pressure and segmental kinematics following a cervical total disc arthroplasty: an in vitro human cadaveric model. Spine (Phila Pa 1976) 30:1165-1172, 2005

20. Eck JC, Humphreys SC, Lim TH, Jeong ST, Kim JG, Hodges $\mathrm{SD}$, et al: Biomechanical study on the effect of cervical spine fusion on adjacent-level intradiscal pressure and segmental motion. Spine (Phila Pa 1976) 27:2431-2434, 2002

21. Ghiselli G, Wharton N, Hipp JA, Wong DA, Jatana S: Prospective analysis of imaging prediction of pseudarthrosis after anterior cervical discectomy and fusion: computed tomography versus flexion-extension motion analysis with intraoperative correlation. Spine (Phila Pa 1976) 36:463-468, 2011

22. Goffin J, van Loon J, Van Calenbergh F, Lipscomb B: A clinical analysis of 4- and 6-year follow-up results after cervical disc replacement surgery using the Bryan Cervical Disc Prosthesis. J Neurosurg Spine 12:261-269, 2010

23. Goffin J, van Loon J, Van Calenbergh F, Plets C: Long-term results after anterior cervical fusion and osteosynthetic stabilization for fractures and/or dislocations of the cervical spine. J Spinal Disord 8:499-508, 1995

24. Gore DR, Sepic SB: Anterior discectomy and fusion for painful cervical disc disease. A report of 50 patients with an average follow-up of 21 years. Spine (Phila Pa 1976) 23:2047-2051, 1998

25. Heller JG, Sasso RC, Papadopoulos SM, Anderson PA, Fessler RG, Hacker RJ, et al: Comparison of BRYAN cervical disc arthroplasty with anterior cervical decompression and fusion: clinical and radiographic results of a randomized, controlled, clinical trial. Spine (Phila Pa 1976) 34:101-107, 2009

26. Hilibrand AS, Carlson GD, Palumbo MA, Jones PK, Bohlman HH: Radiculopathy and myelopathy at segments adjacent to the site of a previous anterior cervical arthrodesis. J Bone Joint Surg Am 81:519-528, 1999

27. Hilibrand AS, Yoo JU, Carlson GD, Bohlman HH: The success of anterior cervical arthrodesis adjacent to a previous fusion. Spine (Phila Pa 1976) 22:1574-1579, 1997

28. Janssen M, Goldstein J, Murrey D, Delamarter R: Heterotropic ossification at the index level after ProDisc-C: what is the clinical significance? Spine J 7 (5 Suppl):48S-49S, 2007 (Abstract)

29. Jorritsma W, Dijkstra PU, de Vries GE, Geertzen JH, Reneman MF: Detecting relevant changes and responsiveness of Neck Pain and Disability Scale and Neck Disability Index. Eur Spine J 21:2550-2557, 2012

30. Katsuura A, Hukuda S, Saruhashi Y, Mori K: Kyphotic malalignment after anterior cervical fusion is one of the factors promoting the degenerative process in adjacent intervertebral levels. Eur Spine J 10:320-324, 2001

31. Kellgren JH: The epidemiology of chronic rheumatism, in Kellgren J, Lawrence J (eds): Atlas of Standard Radiographic Arthritis. Oxford: Blackwell, 1963, pp 14-19

32. Kulkarni V, Rajshekhar V, Raghuram L: Accelerated spondylotic changes adjacent to the fused segment following central cervical corpectomy: magnetic resonance imaging study evidence. J Neurosurg 100 (1 Suppl Spine):2-6, 2004

33. Lee JH, Jung TG, Kim HS, Jang JS, Lee SH: Analysis of the incidence and clinical effect of the heterotopic ossification 
in a single-level cervical artificial disc replacement. Spine J 10:676-682, 2010

34. Leung C, Casey AT, Goffin J, Kehr P, Liebig K, Lind B, et al: Clinical significance of heterotopic ossification in cervical disc replacement: a prospective multicenter clinical trial. Neurosurgery 57:759-763, 2005

35. McAfee PC, Cunningham BW, Devine J, Williams E, Yu-Yahiro J: Classification of heterotopic ossification (HO) in artificial disk replacement. J Spinal Disord Tech 16:384-389, 2003

36. McAfee PC, Reah C, Gilder K, Eisermann L, Cunningham $\mathrm{B}$ : A meta-analysis of comparative outcomes following cervical arthroplasty or anterior cervical fusion: results from 4 prospective multicenter randomized clinical trials and up to 1226 patients. Spine (Phila Pa 1976) 37:943-952, 2012

37. McGrory BJ, Klassen RA: Arthrodesis of the cervical spine for fractures and dislocations in children and adolescents. A long-term follow-up study. J Bone Joint Surg Am 76:16061616,1994

38. Mehren C, Suchomel P, Grochulla F, Barsa P, Sourkova P, Hradil J, et al: Heterotopic ossification in total cervical artificial disc replacement. Spine (Phila Pa 1976) 31:2802-2806, 2006

39. Mummaneni PV, Burkus JK, Haid RW, Traynelis VC, Zdeblick TA: Clinical and radiographic analysis of cervical disc arthroplasty compared with allograft fusion: a randomized controlled clinical trial. J Neurosurg Spine 6:198-209, 2007

40. Murrey D, Janssen M, Delamarter R, Goldstein J, Zigler J, Tay B, et al: Results of the prospective, randomized, controlled multicenter Food and Drug Administration investigational device exemption study of the ProDisc-C total disc replacement versus anterior discectomy and fusion for the treatment of 1-level symptomatic cervical disc disease. Spine J 9:275-286, 2009

41. Park JH, Rhim SC, Roh SW: Mid-term follow-up of clinical and radiologic outcomes in cervical total disk replacement (Mobi-C): incidence of heterotopic ossification and risk factors. J Spinal Disord Tech 26:141-145, 2013

42. Pimenta L, McAfee PC, Cappuccino A, Bellera FP, Link HD: Clinical experience with the new artificial cervical PCM (Cervitech) disc. Spine J 4 (6 Suppl):315S-321S, 2004

43. Pool JJ, Ostelo RW, Hoving JL, Bouter LM, de Vet HC: Minimal clinically important change of the Neck Disability Index and the Numerical Rating Scale for patients with neck pain. Spine (Phila Pa 1976) 32:3047-3051, 2007

44. Pospiech J, Stolke D, Wilke HJ, Claes LE: Intradiscal pressure recordings in the cervical spine. Neurosurgery 44:379385,1999

45. Reitman CA, Hipp JA, Nguyen L, Esses SI: Changes in segmental intervertebral motion adjacent to cervical arthrodesis: a prospective study. Spine (Phila Pa 1976) 29:E221-E226, 2004

46. Robertson JT, Papadopoulos SM, Traynelis VC: Assessment of adjacent-segment disease in patients treated with cervical fusion or arthroplasty: a prospective 2-year study. J Neurosurg Spine 3:417-423, 2005

47. Sasso RC, Anderson PA, Riew KD, Heller JG: Results of cervical arthroplasty compared with anterior discectomy and fusion: four-year clinical outcomes in a prospective, randomized controlled trial. J Bone Joint Surg Am 93:1684-1692, 2011

48. Sears WR, Duggal N, Sekhon LH, Williamson OD: Segmental malalignment with the Bryan cervical disc prosthesiscontributing factors. J Spinal Disord Tech 20:111-117, 2007

49. Smith GW, Robinson RA: The treatment of certain cervicalspine disorders by anterior removal of the intervertebral disc and interbody fusion. J Bone Joint Surg Am 40-A:607-624, 1958
50. Sola S, Hebecker R, Mann S: Bryan cervical disc prosthesis: 5 years follow-up, in SAS Motion Preservation Technology 8th Annual Meeting. Aurora, IL: ISASS, 2008 (Abstract)

51. Suchomel P, Jurák L, Antinheimo J, Pohjola J, Stulik J, Meisel HJ, et al: Does sagittal position of the CTDR-related centre of rotation influence functional outcome? Prospective 2-year follow-up analysis. Eur Spine J 23:1124-1134, 2014

52. Suchomel P, Jurák L, Benes V III, Brabec R, Bradác O, Elgawhary S: Clinical results and development of heterotopic ossification in total cervical disc replacement during a 4-year follow-up. Eur Spine J 19:307-315, 2010

53. Taylor M, Hipp JA, Gertzbein SD, Gopinath S, Reitman CA: Observer agreement in assessing flexion-extension X-rays of the cervical spine, with and without the use of quantitative measurements of intervertebral motion. Spine J 7:654-658, 2007

54. Vaccaro A, Beutler W, Peppelman W, Marzluff JM, Highsmith J, Mugglin A, et al: Clinical outcomes with selectively constrained SECURE-C cervical disc arthroplasty: two-year results from a prospective, randomized, controlled, multicenter investigational device exemption study. Spine (Phila Pa 1976) 38:2227-2239, 2013

55. Vernon H, Mior S: The Neck Disability Index: a study of reliability and validity. J Manipulative Physiol Ther 14:409415, 1991

56. Yang B, Li H, Zhang T, He X, Xu S: The incidence of adjacent segment degeneration after cervical disc arthroplasty (CDA): a meta analysis of randomized controlled trials. PLoS One 7:e35032, 2012

57. Yi S, Kim KN, Yang MS, Yang JW, Kim H, Ha Y, et al: Difference in occurrence of heterotopic ossification according to prosthesis type in the cervical artificial disc replacement. Spine (Phila Pa 1976) 35:1556-1561, 2010

58. Zechmeister I, Winkler R, Mad P: Artificial total disc replacement versus fusion for the cervical spine: a systematic review. Eur Spine J 20:177-184, 2011

59. Zigler JE, Delamarter R, Murrey D, Spivak J, Janssen M: ProDisc-C and anterior cervical discectomy and fusion as surgical treatment for single-level cervical symptomatic degenerative disc disease: five-year results of a Food and Drug Administration study. Spine (Phila Pa 1976) 38:203-209, 2013

\section{Disclosures}

Dr. Suchomel reports that he is a consultant for Aesculap AG. The study was supported financially by Aesculap AG with reimbursement of additional study follow-up expenses to the hospitals.

\section{Author Contributions}

Conception and design: Meisel, Suchomel. Acquisition of data: all authors. Analysis and interpretation of data: Meisel, Jurák, Suchomel. Drafting the article: Meisel, Suchomel. Critically revising the article: Meisel, Jurák, Caroli, Suchomel. Reviewed submitted version of manuscript: Meisel, Jurák, Antinheimo, Arregui, Bruchmann, Čabraja, Kroppenstedt, Kryl, Pohjola, Shackleford, Sola, Stosberg, Stulik, Woiciechowsky, Suchomel. Approved the final version of the manuscript on behalf of all authors: Meisel. Study supervision: Meisel, Suchomel.

\section{Correspondence}

Hans Jörg Meisel, Department of Neurosurgery, BG Clinic Bergmannstrost, Merseburgerstr. 165, Halle 06112, Germany. email: meisel@bergmannstrost.com. 